\title{
Antioxidant Activity of Tomato Powders as Affected by Water Solubility and Application to the Pork Sausages
}

\author{
Hyeong Sang Kim and Koo Bok Chin* \\ Department of Animal Science and Functional Food Research Center, Chonnam National University, \\ Gwangju 500-757, Korea
}

\begin{abstract}
This study was conducted to evaluate the antioxidant activity of oven-dried $\left(60^{\circ} \mathrm{C}\right)$ tomato powder $(\mathrm{TP})$ as affected by water solubility and to evaluate the effects of TP on the physico-chemical properties, and antioxidant and antimicrobial activities of emulsified pork sausages with two levels of TP $(1 \%$ and $2 \%)$. After fresh tomatoes were homogenized and dried at $60^{\circ} \mathrm{C}$ oven, they were extracted by stirring with water. Then, the aqueous solution was filtered, and water soluble and insoluble tomato powders were obtained with freeze drying. In experiment I, total phenolic contents in oven-dried tomato powder, water soluble and insoluble powder were more than $2 \mathrm{~g} / 100 \mathrm{~g}$. The radical scavenging activity and iron-chelation ability of the water-insoluble extracts were higher than those of dried TP and water-soluble extracts. In experiment II, $\mathrm{pH}$ values and Hunter $\mathrm{L}$ values of pork sausages formulated with TP were reduced. However, hunter a and $\mathrm{b}$ values were higher than those of the control, and those effects were increased with increased levels of TP. 2-Thiobarbituric acid reactive substance values of pork sausages containing TP were lower than that of the control during refrigerated storage, regardless of the TP level. These results indicated that TP could be used as a natural color agent and antioxidant in meat products without defects.
\end{abstract}

Key words: tomato powder, antioxidant effect, water solubility, pork sausage

\section{Introduction}

Lipids are a significant functional component role in foods; they influence texture, cooking yield, and water holding capacity (WHC) (Keeton, 1994; Pietrasik, 1999). However, the flavor, color, texture, and nutritional value of foods are frequently diminished as the result of lipid oxidation during storage (Eriksson, 1982). Several studies have aimed to suppress lipid oxidation in food (Park et al., 2008; Wada and Fang, 2002). Synthetic antioxidants, such as butylated hydroxytoluene (BHT) and butylated hydroxyanisole (BHA), have been employed as antioxidants to inhibit lipid oxidation in food. However, these antioxidants might prove harmful to humans (Branen, 1975). Development of natural antioxidants is required for the preparation of substitute synthetic substances.

The tomato is one of the most popular vegetables on Earth and is an important component of several foods. The consumption of tomato and tomato products, such as

\footnotetext{
*Corresponding author: Koo Bok Chin, Department of Animal Science, Chonnam National University, Gwangju 500-757, Korea. Tel: 82-62-530-2121, Fax: 82-62-530-2129, E-mail: kbchin@ channam.ac.kr
}

tomato juice, tomato paste, tomato sauce, tomato soup, and tomato ketchup may help reduce the risk of various cancers (Clinton, 1998). Additionally, the continued consumption of tomato and tomato products is associated with the reduced risk of cancer and heart disease (Giovannucci, 1999). The active anticancer compound in the tomato has been identified as lycopene, the pigment that gives the tomato its red color (Friedman, 2002). Its structure is classified as hydrophobic and it is regarded as a member of the carotenoids. Lycopene can be extracted by strong organic solvents, such as chloroform and benzene (Shi and Maguer, 2000). The lycopene content in tomato products varies (Rao et al., 1998). Moreover, the content and bioavailability of lycopene changes with heating (Dewanto et al., 2002; Gartner et al., 1997; Tonucci et al., 1995).

Tomato also has hydrophilic antioxidants, such as vitamin C (ascorbic acid), and phenolics, such as caffeic acid, rutin, and quercetin (Vallverdú-Queralt et al., 2011). Generally, ascorbic acid and phenolic compounds are the major contributors to the hydrophilic antioxidant activity (Arnao et al., 2001). These antioxidant compounds depend on many factors, such as cultivars, maturity, temperature, and storage condition (Hart and Scott, 1995; Giovanelli 
and Paradiso, 2002).

However, the antioxidant activity of oven-dried tomato powder (TP) as fractionated by water solubility has yet to be thoroughly investigated. The principal objective of this study was to evaluate the antioxidant activity of TP at $60^{\circ} \mathrm{C}$, as well as the antioxidant activity of the watersoluble and -insoluble fractions of TP. In addition, the effects of TP on the physico-chemical properties, and antioxidant and antimicrobial activities of emulsified pork sausages were also evaluated.

\section{Materials and Methods}

\section{Experiment I. Antioxidant activity of TP as affected by water solubility}

\section{Materials}

Fresh ripened tomatoes (Lycopersicon esculentum Mill), cultivated in Damyang, Jeonnam province, Korea, were purchased from a wholesale market in Gwangju, Korea. Folin-Ciocalteau reagent, 1,1-diphenyl-2-pycrylhydrazyl (DPPH)-radical, ethylene diaminetetraacetic acid (EDTA), and 2-thiobarbituric acid (TBA) were obtained from SigmaAldrich (Steinheim, Germany). Gallic acid, ferrous chloride, ferric chloride, trichloroacetic acid (TCA), and petroleum ether were purchased from Junsei Chemical (Japan). Ascorbic acid was obtained from Samchun Chemical (Korea). Potassium ferricyanide was obtained from Avocado Research Chemicals (UK).

\section{Preparation of TP}

Thoroughly washed tomatoes were chopped and homogenized prior to drying at $60^{\circ} \mathrm{C}$ using a hot air oven (LDO250F, Labtech, Ltd., Korea). The obtained powder was used as the dried TP. Subsequently, the TP was mixed with distilled deionized water (dd-water) at a dried TP-towater ratio of 1:20. The mixture was stirred at room temperature for $24 \mathrm{~h}$ prior to filtering through Whatman No. 42 paper. The extraction process was repeated twice and all filtrates were pooled prior to lyophilization to obtain the water-soluble powder. Additionally, these powders were also used for lyophilization to obtain the waterinsoluble powders. FT5505 freeze dryer (Ilshin co. LTD, Korea) was used for lyophilization under $-50^{\circ} \mathrm{C}$ temperature and $7 \mathrm{mmTorr}$ vacuum condition. All powders were stored at $-70^{\circ} \mathrm{C}$ until used.

Total phenolic content

The contents of total phenolic compounds of TP, water soluble and insoluble tomato powders were determined using the Folin-Ciocalteu method (Lin and Tang, 2007) with slight modification. TP $(0.1 \mathrm{~g})$ was mixed with 10 $\mathrm{mL}$ of dd-water. Then, $0.1 \mathrm{~mL}$ of this mixture was mixed further with dd-water $(2.8 \mathrm{~mL}), 2 \% \mathrm{Na}_{2} \mathrm{CO}_{3}(2 \mathrm{~mL})$, and $50 \%$ Folin-Ciocalteau reagent $(0.1 \mathrm{~mL})$ prior to vortexing. After 30 min of incubation of the mixture at room temperature, the absorbance of the mixture was measured at $750 \mathrm{~nm}$ using a spectrophotometer (UV-1601, Shimadzu, Japan). Gallic acid was used as a standard $(0-200 \mathrm{mg} / \mathrm{L})$. The total phenolics were expressed as the gallic acid equivalents (GAE)/100 g dried powder.

\section{DPPH radical scavenging activity}

The radical scavenging activity of TPs was measured on the basis of their ability to scavenge DPPH radicals, which was determined according to the method described by Huang et al. (2006). Approximately $4 \mathrm{~mL}$ of each mixture $(0.5-20 \mathrm{mg} / \mathrm{mL}$ in dd-water) was mixed with $1 \mathrm{~mL}$ of $0.2 \mathrm{mM}$ methanolic DPPH radical solution. After vortexing, the mixtures were incubated at room temperature for $30 \mathrm{~min}$ in darkness. Then, the absorbance at $517 \mathrm{~nm}$ was measured. Ascorbic acid was used as a reference. The scavenging activity $(\%)$ was calculated as $\left[\left(\Delta A_{517}\right.\right.$ of control $-\Delta A_{517}$ of sample $) \div \Delta A_{517}$ of control $] \times 100$.

\section{Ferrous iron chelating ability}

The ferrous iron chelating ability of all TPs was determined by measuring the inhibition of the formation of a $\mathrm{Fe}^{2+}$-ferrozine complex as described previously (Le et al., 2007). A $0.5 \mathrm{~mL}$ volume of each mixture $(0.5-20 \mathrm{mg} / \mathrm{mL}$ in dd-water), $0.6 \mathrm{mM}$ ferrous chloride $(0.1 \mathrm{~mL})$, and methanol $(0.9 \mathrm{~mL})$ were combined and allowed to react for $5 \mathrm{~min}$ at room temperature. After the reaction, ferrozine ( $0.1 \mathrm{~mL}, 5 \mathrm{mM}$ in methanol) was added and all samples were allowed to react for $10 \mathrm{~min}$ at room temperature. The absorbance of the $\mathrm{Fe}^{2+}$-ferrozine complex was then measured at $562 \mathrm{~nm}$. EDTA was used as the reference and the chelating activity $(\%)$ was calculated as $\left[\left(\Delta A_{562}\right.\right.$ of control $-\Delta A_{562}$ of sample $) \div \Delta A_{562}$ of control] $\times 100$.

\section{Reducing power}

The reducing power was measured via the method described by Huang et al. (2006). Each mixture contained $2.5 \mathrm{~mL}$ of TP $(1-20 \mathrm{mg} / \mathrm{mL}), 2.5 \mathrm{~mL}$ of sodium phosphate buffer $(0.2 \mathrm{M}, \mathrm{pH} 6.6)$, and $2.5 \mathrm{~mL}$ of potassium ferricyanide $(10 \mathrm{mg} / \mathrm{mL})$. The mixture was incubated for $20 \mathrm{~min}$ at $50^{\circ} \mathrm{C}$. Then, $2.5 \mathrm{~mL}$ of trichloroacetic acid (TCA; $100 \mathrm{mg} / \mathrm{mL}$ ) was added and the mixture was cen- 
trifuged for $10 \mathrm{~min}$ at $200 \times \mathrm{g}$. Consequently, the upper layer $(5 \mathrm{~mL})$ was mixed with $5 \mathrm{~mL}$ of dd-water and $1 \mathrm{~mL}$ of ferric chloride $(1 \mathrm{mg} / \mathrm{mL})$. The absorbance at $700 \mathrm{~nm}$ was measured and high levels of absorbance were regarded as reflective of high reducing power.

\section{Antioxidant activity in linoleic acid emulsion}

The antioxidant activity of TPs in linoleic acid emulsion was determined using the method described by Yen and Heish (1998). Linoleic acid emulsion was prepared via the mixing of $0.2804 \mathrm{~g}$ of linoleic acid, $0.2804 \mathrm{~g}$ of Tween 20 as emulsifier, and $50 \mathrm{~mL}$ phosphate buffer $(0.2$ $\mathrm{M}, \mathrm{pH} 7.0)$ prior to homogenization. Each sample $(0.5 \mathrm{~mL}$ at the concentration of 10,30 , and $50 \mathrm{mg} / \mathrm{mL}$ ) was mixed with $2.5 \mathrm{~mL}$ of linoleic acid emulsion and $2 \mathrm{~mL}$ of phosphate buffer $(0.2 \mathrm{M}, \mathrm{pH} 7.0)$ prior to incubation at $37^{\circ} \mathrm{C}$. Aliquots of $0.1 \mathrm{~mL}$ were taken at various incubation times. The degree of oxidation was measured using the thiocyanate method. Subsequently, $4.7 \mathrm{~mL}$ of ethanol $(75 \%)$, ammonium thiocyanate $(0.1 \mathrm{~mL}, 30 \%)$, sample solution $(0.1 \mathrm{~mL})$, and ferrous chloride $(0.1 \mathrm{~mL}, 0.02 \mathrm{M}$ in $3.5 \%$ $\mathrm{HCl}$ ) were added. The mixture was maintained for $3 \mathrm{~min}$ at room temperature, and the peroxide value was determined by reading the absorbance at $500 \mathrm{~nm}$. A high absorbance at $500 \mathrm{~nm}$ indicated low antioxidant activity. A control was prepared in the same manner, except that the extracts were omitted. Additionally, BHT was also employed as a positive control.

\section{Statistical analyses}

Data were analyzed by two-way analysis of variance (ANOVA) using SPSS 18.0 for Windows (SPSS, IL) as factors for treatments (reference, TP, water-soluble tomato extract and water-insoluble tomato extract) and concentration $(0,0.5,1,2.5,5,10$, and $20 \mathrm{mg} / \mathrm{mL})$. Significant differences among means were analyzed by Duncan's multiple range test at a level of $0.05 \%$.

\section{Experiment II. Evaluation of physico-chemical and antioxidant properties of pork sausages with oven dried TP}

\section{Materials}

Fresh tomatoes were washed and homogenized using a homogenizer (AM-8, Nihonseiki, Japan). The tomato mixture was dried at $60^{\circ} \mathrm{C}$ using a dry oven (LDO-250F, Labtech, Korea). Pork ham from crossbred (Landrace $\times$ Large Yorkshire) and back fat that had been slaughtered the previous day were purchased from a wholesale meat market in Gwangju, South Korea. The excessive fat and connective tissue of pork ham were removed and a grinder (M-12s, Fujee Plant, Korea) was used for grinding. The ground ham and fat were stored at $-50^{\circ} \mathrm{C}$ until used.

\section{Processing of pork sausages}

The pork sausages were manufactured with different amounts $(1 \%$ and $2 \%)$ of oven dried TP at $60^{\circ} \mathrm{C}$ (Table 1). Trimmed pork hams were chopped for $30 \mathrm{sec}$ using a blender (K55, Crypto Peerless, UK). Sodium chloride, sodium erythorbate, sodium nitrite, and ice water were added to the minced pork ham and homogenized. To extract salt soluble protein, this mixture was further cut with pork back fat, sugar, spices, non-fat dry milk, TP, and ice water. The resulting meat batter was then vacuumpackaged and stuffed into polyvinylidene chloride casing

Table 1. Formulation of pork sausages with two levels of TP

\begin{tabular}{|c|c|c|c|c|}
\hline \multirow{2}{*}{ Ingredients } & \multicolumn{4}{|c|}{ Treatments } \\
\hline & CTL (g) & REF (g) & TRT 1 (g) & TRT $2(\mathrm{~g})$ \\
\hline Raw meat & 550 & 550 & 550 & 550 \\
\hline Fat & 200 & 200 & 200 & 200 \\
\hline Water & 190 & 190 & 190 & 190 \\
\hline Salt & 13 & 13 & 13 & 13 \\
\hline Sodium tripolyphosphate & 4 & 4 & 4 & 4 \\
\hline Cure blend & 2.5 & 2.5 & 2.5 & 2.5 \\
\hline Sodium erythorbate & 0.5 & 0.5 & 0.5 & 0.5 \\
\hline Sugar & 10 & 10 & 10 & 10 \\
\hline Spices & 10 & 10 & 10 & 10 \\
\hline Nonfat dry milk & 10 & 10 & 10 & 10 \\
\hline Corn syrup & 10 & 10 & 10 & 10 \\
\hline Butylated hydroxytolune (BHT) & - & 0.1 & - & - \\
\hline Tomato powder & - & - & 10 & 20 \\
\hline Total & $1,000.0$ & $1,000.1$ & $1,010.0$ & $1,020.0$ \\
\hline
\end{tabular}


(D-755R, 40 micron gauge, $46 \mathrm{~mm}$; Japan), boiled, and cooked until an internal temperature of $72^{\circ} \mathrm{C}$ was reached in a water bath (WB-22, Daihan Scientific, Korea). The boiled pork sausages were then chilled for $15 \mathrm{~min}$ with ice water. After cool-down, all sausages were air-packaged and stored at $10^{\circ} \mathrm{C}$ until analysis after $0,3,7,14,21$, and $28 \mathrm{~d}$.

\section{Proximate analyses}

Moisture, fat, protein, and crude ash contents (all in \%) were measured according to AOAC protocols (1995) procedures. Moisture content was measured using the dry oven method. Fat content was measured using the Soxhlet extraction method. Protein content was measured using the Kjeldahl method (PRO-NITRO S; J.P. Selecta, Spain). Crude ash content was analyzed using a muffle furnace.

\section{Texture profile analysis (TPA)}

A model 3344 universal testing machine (Instron, Canton, USA) was used for TPA. Sausage samples $13 \mathrm{~mm}$ in height and $12.5 \mathrm{~mm}$ in diameter were prepared using a puncturing apparatus. Hardness (gf), springiness (cm), gumminess (hardness $\times$ cohesiveness), chewiness (hardness $\times$ cohesiveness $\times$ springiness), and cohesiveness (ratio of active work done under the second compression curve to that done under the first compression curve) were calculated as previously detailed (Bourne, 1978). Two compression test cycles were performed with $75 \%$ of sample height with a $500 \mathrm{~N}$ load cell at a cross-speed of $300 \mathrm{~mm} /$ min.

\section{$\mathrm{pH}$ values and color measurement}

$\mathrm{pH}$ values of samples were measured using a $\mathrm{pH}$-meter (MP-120, Mettler-Toledo, Switzerland). The color values of sausage samples surface were measured using a model CR-10 color reader (Minolta, Japan). Color values were expressed by Hunter L (lightness), a (redness), and b (yellowness). Data were expressed as the mean of five measurements of each sausage sample (White plate standard: $\mathrm{L}=92.1, \mathrm{a}=1.00, \mathrm{~b}=-2.07)$.

\section{Microbial counts}

Total plate count (TPC) agar and violet red bile (VRB) agar were prepared for the determination of total bacterial counts and Enterobacteriaceae, respectively (Chin et al., 2006). Homogenized pork patties ( $10 \mathrm{~g}$ ) were mixed with $90 \mathrm{~mL}$ of sterilized dd-water and serial dilutions were made. Aliquots $(0.1 \mathrm{~mL})$ of each dilution were inoculated into the TPC and VRB agars. They were incubated at $37^{\circ} \mathrm{C}$ for $2 \mathrm{~d}$ and the resulting growth was enumerated as $\log$ colony forming units (CFU)/g.

Thiobarbituric acid reactive substances (TBARS) Malondialdehyde generated by lipid oxidation was evaluated by TBARS values as described by Shinnhuber and Yu (1977). Approximately $2 \mathrm{~g}$ of each homogenized sample was transferred to a screw cap test tube. To inhibit lipid oxidation during the TBARS procedure, $0.5 \mathrm{~mL}$ of antioxidant solution ( $0.6 \mathrm{~g}$ BHA in $10.8 \mathrm{~g}$ propylene glycol and $0.6 \mathrm{~g}$ BHT in $8.0 \mathrm{~g}$ warm Tween 20) was added to tubes containing $3 \mathrm{~mL}$ of $1 \%$ TBA solution. Seventeen milliliters of $2.5 \%$ TCA solution was added to the mixture. After vortexing, the mixture was heated for $30 \mathrm{~min}$ at $100^{\circ} \mathrm{C}$, and cooled down at room temperature. Approximately $5 \mathrm{~mL}$ of mixture in the upper part was transferred into a centrifuge tube with $5 \mathrm{~mL}$ of chloroform. After the test tube was vortexed for $1 \mathrm{~min}$ and then centrifuged at $200 \times g$ for $5 \mathrm{~min}, 3 \mathrm{~mL}$ of upper phase was transferred to another centrifuge tube with $3 \mathrm{~mL}$ of petroleum ether. The test tube was vortexed for $1 \mathrm{~min}$ and centrifuged again for $10 \mathrm{~min}$. The reactive substances were measured using a UV-1601 spectrophotometer (Shimadzu). The TBARS value (mg malondialdehyde/ $\mathrm{kg}$ ) was calculated as (optical density $\left.(\text { O.D. })_{532 \mathrm{~nm}} \times 9.48\right) \div$ sample weight $(\mathrm{g})$.

\section{Statistical analyses}

Data were analyzed using SPSS 18.0 program for Windows. One-way analysis of variance (ANOVA) was used for proximate analysis and TPA. Two-way ANOVA was used for $\mathrm{pH}$, color, TBARS, and microbial counts as factors for treatment (control, reference (BHT 0.01\%), with 1 or $2 \%$ of $60^{\circ} \mathrm{C}$ TP and storage time $(0,3,7,14,21$, and $28 \mathrm{~d}$ ). Significant differences among the means were analyzed by Duncan's multiple range test $(p<0.05)$.

\section{Results and Discussion}

\section{Experiment I. Antioxidant activity of TP as affected by water solubility}

Total phenolic contents and yield

Total phenolic content and yield for the three types of TPs are summarized in Table 2. The recovery yield of dried TP was $6.88 \%$ (based on fresh tomato, wet basis). Consequently, the lyophilized powders derived from water-soluble and water-insoluble parts were measured at $57.5 \%$ and $31.0 \%$, respectively. The total yield of water- 
Table 2. Contents (g/100 g) of total phenolic compounds and recovery yield from tomato powders as affected by water solubility

\begin{tabular}{cccc}
\hline \hline & & Treatments ${ }^{\mathrm{I}}$ & \\
\cline { 2 - 4 } & TP & Water soluble & Water insoluble \\
\hline Total phenolic contents (g/100g) & $2.16^{\mathrm{a}} \pm 0.29$ & $2.18^{\mathrm{a}} \pm 0.16$ & $2.34^{\mathrm{a}} \pm 0.27$ \\
Dry yield (\%, powder) & 6.88 & - & - \\
Extraction yield (\%) & - & $57.5^{\mathrm{a}}$ & $31.0^{\mathrm{b}}$ \\
Total yield (\%) & - & $3.96^{\mathrm{a}}$ & $2.13^{\mathrm{b}}$ \\
\hline
\end{tabular}

\footnotetext{
${ }^{a, b}$ Means with different superscripts in the same row are different $(p<0.05)$.

${ }^{1)}$ Treatments: TP, dried tomato powder in a $60^{\circ} \mathrm{C}$ oven; Water-soluble, water-soluble extracts from dried tomato powder in a $60^{\circ} \mathrm{C}$ oven; Water-insoluble, water-insoluble extracts from dried tomato powder in a $60^{\circ} \mathrm{C}$ oven.
}

soluble and water-insoluble powders were $3.96 \%$ and $2.13 \%$, respectively. The contents of total phenolic compounds of all TPs exceeded $2 \%$. However, no statistical differences were noted $(p>0.05)$. Toor and Savage (2006) reported that the contents of total phenolic compounds from the soluble fractions of semi-dried tomatoes were higher than those of the insoluble counterparts. Additionally, the contents of total phenolic compounds of soluble fractions from fresh tomato, tomato pulp, and tomato paste were higher than those insoluble counterparts when phosphate buffers with different $\mathrm{pH}$ values were used as an extraction solvent (Lavelli et al., 2000). The present results differed; total phenolic compound content was similar in the water-soluble and -insoluble fractions. The discrepancy may reflect the different extraction solvents (water and phosphate buffers) and extraction methods. Therefore, both the hydrophilic/hydrophobic properties and $\mathrm{pH}$ values of the extraction solvent might perform important functions in the extraction of phenolic compounds from tomato matrix.

\section{DPPH radical scavenging activity}

Since there was an interaction $(p<0.05)$ between two factors (treatment and concentration) in the DPPH radical scavenging activity results, data were separated out and the treatment was assessed in terms of concentration (Table 3). The DPPH radical scavenging activity of three types of TPs increased with increasing concentrations (Table 3). The most effective antioxidant activities were observed in the water-insoluble powder; this powder displayed the highest antioxidant activity, regardless of concentration $(p<0.05)$. Additionally, the antioxidant activity of the insoluble fractions at concentrations above $5 \mathrm{mg} / \mathrm{mL}$ was comparable to those of ascorbic acid, which was used as a reference (Table 3). Basuny et al. (2009) reported that DPPH radical scavenging activity increased with increasing lycopene contents. This suggested that lycopene was probably the active compound responsible for the DPPH radical scavenging activity. Hydrophobic compounds in tomato, such as lycopene, are not solubilized in hydrophilic solvents, such as water (Shi, 2002). These results indicate that the water-insoluble fractions

Table 3. Antioxidant activities of tomato as affected by different water solubility

\begin{tabular}{|c|c|c|c|c|c|c|c|c|}
\hline \multirow{2}{*}{ Parameters } & \multirow{2}{*}{ Treatments $^{1)}$} & \multicolumn{7}{|c|}{ Concentration (mg/mL) } \\
\hline & & 0 & 0.5 & 1 & 2.5 & 5 & 10 & 20 \\
\hline \multirow{4}{*}{$\begin{array}{c}\text { DPPH radical } \\
\text { scavenging activity }(\%)\end{array}$} & AA & $0.00^{\mathrm{bZ}}$ & $92.9^{\mathrm{aY}}$ & $93.5^{\mathrm{ax}}$ & $93.5^{\mathrm{aW}}$ & $92.5^{\mathrm{aY}}$ & $93.3^{\mathrm{aX}}$ & $93.5^{\mathrm{ax}}$ \\
\hline & $\mathrm{TP}$ & $0.00^{\mathrm{dZ}}$ & $26.3^{\mathrm{cZ}}$ & $30.6^{\mathrm{cZ}}$ & $34.1^{\mathrm{cY}}$ & $40.8^{\mathrm{cZ}}$ & $60.9^{\mathrm{bY}}$ & $81.8^{\mathrm{aY}}$ \\
\hline & Soluble & $0.00^{\mathrm{eZ}}$ & $21.1^{\mathrm{dZ}}$ & $23.9^{\mathrm{cd} Z}$ & $24.9^{\mathrm{cd} Z}$ & $28.9^{\mathrm{cZ}}$ & $36.2^{\mathrm{bZ}}$ & $49.2^{\mathrm{aZ}}$ \\
\hline & Insoluble & $0.00^{\mathrm{eZ}}$ & $24.2^{\mathrm{dZ}}$ & $43.9^{\mathrm{cY}}$ & $77.6^{\mathrm{bX}}$ & $98.0^{\mathrm{aY}}$ & $100^{\mathrm{aX}}$ & $97.7^{\mathrm{aX}}$ \\
\hline \multirow{4}{*}{$\begin{array}{l}\text { Iron chelating } \\
\text { activity }(\%)\end{array}$} & EDTA & $0.00^{\mathrm{bZ}}$ & $99.4^{\mathrm{aY}}$ & $99.4^{\mathrm{aY}}$ & $99.5^{\mathrm{aY}}$ & $99.3^{\mathrm{aY}}$ & $99.3^{\mathrm{aX}}$ & $99.5^{\mathrm{aZ}}$ \\
\hline & $\mathrm{TP}$ & $0.00^{\mathrm{cZ}}$ & $34.4^{\mathrm{bZ}}$ & $33.3^{\mathrm{bZ}}$ & $45.1^{\mathrm{bZ}}$ & $58.0^{\mathrm{abZ}}$ & $76.8^{\mathrm{aZ}}$ & $79.7^{\mathrm{aZ}}$ \\
\hline & Soluble & $0.00^{\mathrm{eZ}}$ & $29.6^{\mathrm{dZ}}$ & $34.6^{\mathrm{cd} Z}$ & $46.5^{\mathrm{cZ}}$ & $62.5^{\mathrm{bZ}}$ & $79.4^{\mathrm{aYZ}}$ & $90.8^{\mathrm{aZ}}$ \\
\hline & Insoluble & $0.00^{\mathrm{dZ}}$ & $37.9^{\mathrm{cZ}}$ & $29.8^{\mathrm{cZ}}$ & $47.1^{\mathrm{cZ}}$ & $82.1^{\mathrm{bYZ}}$ & $92.7^{\mathrm{abXY}}$ & $99.5^{\mathrm{aZ}}$ \\
\hline \multirow{4}{*}{$\begin{array}{l}\text { Reducing Power } \\
\text { (O.D) }\end{array}$} & $\mathrm{AA}$ & $0.09^{\mathrm{bZ}}$ & $3.42^{\mathrm{aY}}$ & $3.46^{\mathrm{aY}}$ & $3.44^{\mathrm{aY}}$ & $3.35^{\mathrm{aY}}$ & $3.20^{\mathrm{a} Z}$ & - \\
\hline & $\mathrm{TP}$ & $0.09^{\mathrm{eZ}}$ & $0.24^{\mathrm{deZ}}$ & $0.33^{\mathrm{dZ}}$ & $0.69^{\mathrm{cZ}}$ & $1.17^{\mathrm{bZ}}$ & $2.24^{\mathrm{aZ}}$ & - \\
\hline & Soluble & $0.09^{\mathrm{dZ}}$ & $0.26^{\mathrm{dZ}}$ & $0.36^{\mathrm{dZ}}$ & $0.75^{\mathrm{cZ}}$ & $1.29^{\mathrm{bZ}}$ & $2.22^{\mathrm{aZ}}$ & - \\
\hline & Insoluble & $0.09^{\mathrm{dZ}}$ & $0.28^{\mathrm{dZ}}$ & $0.32^{\mathrm{dZ}}$ & $0.65^{\mathrm{cZ}}$ & $1.09^{\mathrm{bZ}}$ & $1.89^{\mathrm{aZ}}$ & - \\
\hline
\end{tabular}

${ }^{a-e}$ Means with different superscripts in the same row are different $(p<0.05)$.

${ }^{\mathrm{W}-\mathrm{Z}}$ Means with different superscripts in the same column are different $(p<0.05)$.

${ }^{1)}$ Treatments: AA, L-ascorbic acid; TP, dried tomato powder at $60^{\circ} \mathrm{C}$ oven; Soluble, water-soluble extracts from dried tomato powder at $60^{\circ} \mathrm{C}$ oven; Insoluble, water-insoluble extracts from dried tomato powder at $60^{\circ} \mathrm{C}$ oven; EDTA, Ethylendiaminetetraacetic acid 
might contain higher levels of lycopene than the watersoluble counterpart. Thus, DPPH radical scavenging activity was distinctive in the water-insoluble powder rather than the water-soluble counterpart.

\section{Iron chelating ability}

The iron-chelating ability of all TPs increased with increasing concentrations $(p<0.05)$ and over $50 \%$ iron chelation activity was also noted at concentrations exceeding $5 \mathrm{mg} / \mathrm{mL}$ (Table 3). Water-insoluble TP at concentrations ranging from $5-20 \mathrm{mg} / \mathrm{mL}$ displayed activity comparable to those of the reference (EDTA). However, efficacy similar to that of the reference was observed only at the highest concentration $(20 \mathrm{mg} / \mathrm{mL})$ when $\mathrm{TP}$ and water-soluble powder were used. This indicated that the insoluble powder possessed more profound activity than the other samples. The lipophilic substances in waterinsoluble powder would likely be the most active compound in terms of the suppression of lipid oxidation. These results were generally consistent with those reported by Lavelli et al. (2000), who evaluated the lipid peroxidation catalyzed by copper in the presence of tomato products (fresh tomato, tomato puree, tomato paste). The authors also noted that increasing concentrations of the lipophilic fraction resulted in an increased lipid oxidation-inhibitory effect. Most (90\%) of the carotenoids in tomato are lycopene, the lipophilic pigment (Shi, 2002). Thus, it can be suggested that lycopene is the active compound present in the water-insoluble fraction that actively chelates metal iron, thereby inhibiting lipid oxidation. Lavelli et al. (2000) also noted that the hydrophilic fractions of tomato samples can function as pro-oxidants because they contain more ascorbic acid contents than the hydrophobic fractions. However, ascorbic acid is a thermally labile substance, and is most probably degraded upon oven drying (Dewanto et al., 2002). Lee (1992) reported that the intermediate and final products from the Maillard reaction could be the antioxidants. Moreover, an increase in the antioxidant activity of heat-treated tomato juice was observed as the result of the Maillard reaction (Anese et al., 1999). Therefore, the iron chelation ability of the water-soluble fractions might be higher than those of the water-insoluble components, due to the production of antioxidants resulting from the Maillard reaction.

\section{Reducing power}

The reducing power of each TP was measured as the absorbance at $700 \mathrm{~nm}$. All values were higher than 0.5 from concentrations of $2.5-20 \mathrm{mg} / \mathrm{mL}$, considered an ac- ceptable range (Lin et al., 2009). The reducing power of all powders was increased with increasing concentrations (Table 3). No statistical differences among the tomato samples were observed at the same concentrations, regardless of the type of TP used, whereas the AA samples maintained higher reducing power than the treatments at concentrations below $5 \mathrm{mg} / \mathrm{mL}(p>0.05)$. Nilsson et al. (2005) measured the 2, 2'-azino-bis (3-ethylbenzthiazoline-6-sulphonic acid) (ABTS) radical cation decolorization activity and ferric iron reducing power of hydrophilic and lipophilic extracts from various vegetables, including fresh tomatoes. The hydrophilic fractions displayed higher reducing power than the lipophilic fractions $(p<0.05)$. In our study, active reducing agents were present at similar proportions in the lipophilic and lipophobic fractions. Gahler et al. (2003) previously determined that the reducing power of tomato extracts increased when the phenolic content was increased. These results indicated that phenolic compounds might affect the reducing power. Since similar phenolic compound contents were presently found in both the water-soluble and -insoluble parts, the ability to reduce ferric ion could be observed accordingly. Our results also demonstrated that hydrophobic and hydrophilic phenols were present at equal levels in dried TP.

\section{Antioxidant activity in linoleic acid emulsion}

The results of linoleic acid peroxidation in the presence

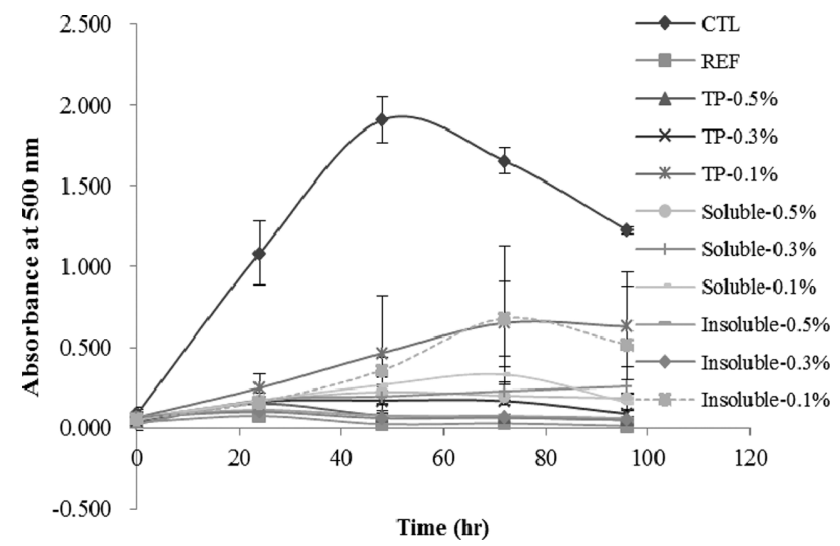

Fig. 1. Antioxidant activity of dried tomato powder as affected by water solubility in linoleic acid emulsion system. High absorbance at $500 \mathrm{~nm}$ indicates low antioxidant activity. CTL, control; REF, reference (BHT 0.01\%); TP$0.5 \%, 0.5 \%$ of dried tomato powder (TP) at $60^{\circ} \mathrm{C}$ oven; TP- $0.3 \%, 0.3 \%$ of TP; TP- $0.1 \%, 0.1 \%$ of TP; Soluble$0.5 \%, 0.5 \%$ of tomato water-soluble fraction (TWSF) from TP; Soluble- $0.3 \%, 0.3 \%$ of TWSF from TP; Soluble- $0.1 \%$, $0.1 \%$ of TWSF from TP; Insoluble- $0.5 \%, 0.5 \%$ of tomato water-insoluble fraction (TWIF) from TP; Insoluble$0.3 \%, 0.3 \%$ of TWIF from TP; Insoluble- $0.1 \%, 0.1 \%$ of TWIF from TP. 
of the three types of TPs are presented in Fig. 1. The high absorbance at $500 \mathrm{~nm}\left(\mathrm{Abs}_{500}\right)$ was considered reflective of high levels of peroxide formation. The control $\mathrm{Abs}_{500}$ increased with increasing length of incubation at $37^{\circ} \mathrm{C}$, with the maximum value, reflecting the highest amount of lipid peroxides, observed at $48 \mathrm{~h}$. Further incubation of the sample for up to $96 \mathrm{~h}$ resulted in a degradation-mediated reduction of lipid peroxides, resulting in secondary oxidation products. Lipid peroxidation could be suppressed during the incubation period by the addition of TPs. The water-soluble fraction seemed to demonstrate that the highest effective level was noted at a concentration of $0.1 \%$. However, an effect comparable to that have shown in the reference, $0.01 \%$ of BHT, was observed at $0.3 \%$ and $0.5 \%$, regardless of the type of powder used. This suggested that all powders could be used effectively at concentrations over $0.3 \%$. Lavelli et al. (2000) reported that the inhibitory activity of peroxidation was increased with increasing concentrations of the hydrophilic and lipophilic fractions extracted from tomatoes.

\section{Experiment II. Evaluation of physico-chemical and antioxidant properties of pork sausages with oven dried TP}

\section{Proximate analyses}

As shown in Table 4, there were no differences among the treatment in the chemical composition $(p>0.05)$. The effect of various levels $(5,10$, and $15 \%)$ of TP on the physical and chemical characteristic of beef patties was reported by Candogan (2002). Addition of $15 \%$ TP resulted in higher moisture and ash, whereas lower protein content as compared to the control. Since low level of dried-tomato powders ( 1 and $2 \%$ ) were incorporated into the pork sausage, the chemical composition of sausage samples might not affect.

\section{TPA}

As shown in Table 5, addition of TP to the pork sausage did not affect the TPA parameters $(p>0.05)$. Cell wall component such as pectin could responsible for the changes in texture, since this component retain water during the cooking. Cell wall polysaccharides of tomato are effective contributors to texture, since pectins form gels and influence the viscosity (Cámara-Hurtado et al., 2002). These cell wall pectin components could increase moisture content and improve texture (Bázan-Lugo et al., 2012). In this study, however, cell wall components of TP did not increase moisture content and did not affect texture parameters.

\section{$\mathrm{pH}$ and color}

The changes of $\mathrm{pH}$ and color of sausage samples with TP were listed in Table 6. Addition of TP decreased $\mathrm{pH}$ value of sausage sample $(p<0.05)$ and $2 \%$ TP showed the lowest $\mathrm{pH}$ value among the treatment. $\mathrm{pH}$ values tended to increase with increasing storage time $(p<0.05)$. Similar results have been reported by related research. Addition of dry tomato peel to beef hamburger decreased the $\mathrm{pH}$ values in a concentration-dependent manner (Garcia et al., 2009). Deda et al. (2007) added tomato paste to frankfurter and a decrease in $\mathrm{pH}$ values was also observed. Low $\mathrm{pH}$ values of TP (4.25-4.26) might influence lower $\mathrm{pH}$ values of sausage sample as compared to the control.

Sausage samples with TP showed different color parameters as compared to the control. The lightness was decreased and redness and yellowness were increased in treatments containing TP than the control in a concentration-dependent manner $(p<0.05)$. Increasing storage time increased lightness, whereas redness decreased. A similar result also observed by Candogan (2002) when tomato paste was added to the beef patty. Lightness (L) value decreased with increasing tomato paste concentration,

Table 4. Proximate composition of pork sausages with two levels of TP

\begin{tabular}{|c|c|c|c|c|c|}
\hline \multirow{2}{*}{\multicolumn{2}{|c|}{ Parameters (\%) }} & \multicolumn{4}{|c|}{ Treatments ${ }^{1)}$} \\
\hline & & CTL & REF & TRT 1 & TRT 2 \\
\hline \multirow{2}{*}{ Moisture } & Mean & $62.0^{\mathrm{a}}$ & $63.2^{\mathrm{a}}$ & $61.6^{\mathrm{a}}$ & $61.1^{\mathrm{a}}$ \\
\hline & $\mathrm{SD}$ & 0.92 & 2.50 & 0.85 & 0.06 \\
\hline \multirow{2}{*}{ Fat } & Mean & $19.9^{\mathrm{a}}$ & $20.0^{\mathrm{a}}$ & $20.3^{\mathrm{a}}$ & $18.7^{\mathrm{a}}$ \\
\hline & $\mathrm{SD}$ & 1.43 & 2.38 & 1.02 & 0.92 \\
\hline \multirow{2}{*}{ Protein } & Mean & $12.3^{\mathrm{a}}$ & $12.6^{\mathrm{a}}$ & $12.4^{\mathrm{a}}$ & $12.5^{\mathrm{a}}$ \\
\hline & $\mathrm{SD}$ & 0.18 & 0.40 & 0.16 & 0.08 \\
\hline \multirow{2}{*}{ Ash } & Mean & $2.64^{\mathrm{a}}$ & $2.73^{\mathrm{a}}$ & $2.72^{\mathrm{a}}$ & $2.83^{\mathrm{a}}$ \\
\hline & SD & 0.08 & 0.03 & 0.05 & 0.15 \\
\hline
\end{tabular}

Means with same superscript in the same row is not different $(p>0.05)$.

${ }^{1)}$ Treatments: As shown in Table 1. 
Table 5. Textural properties of pork sausages with two levels of TP

\begin{tabular}{|c|c|c|c|c|c|}
\hline \multirow{2}{*}{\multicolumn{2}{|c|}{ Parameters }} & \multicolumn{4}{|c|}{ "Treatments ${ }^{1)}$} \\
\hline & & \multirow{2}{*}{$\frac{\text { CTL }}{2181^{\mathrm{a}}}$} & \multirow{2}{*}{$\frac{\text { REF }}{2291^{\mathrm{a}}}$} & \multirow{2}{*}{$\begin{array}{l}\text { TRT 1 } \\
2094^{\mathrm{a}}\end{array}$} & \multirow{2}{*}{$\frac{\text { TRT } 2}{2013^{\mathrm{a}}}$} \\
\hline & Mean & & & & \\
\hline Hardness (gt) & SD & 458 & 292 & 420 & 330 \\
\hline \multirow{2}{*}{ Springiness (mm) } & Mean & $4.32^{\mathrm{a}}$ & $5.12^{\mathrm{a}}$ & $5.02^{\mathrm{a}}$ & $4.35^{\mathrm{a}}$ \\
\hline & $\mathrm{SD}$ & 1.13 & 0.15 & 0.29 & 0.02 \\
\hline \multirow{2}{*}{ Gumminess } & Mean & $19.7^{\mathrm{a}}$ & $15.6^{\mathrm{a}}$ & $16.6^{\mathrm{a}}$ & $12.6^{\mathrm{a}}$ \\
\hline & SD & 8.65 & 0.97 & 1.18 & 2.85 \\
\hline \multirow{2}{*}{ Chewiness } & Mean & $78.0^{\mathrm{a}}$ & $93.1^{\mathrm{a}}$ & $84.6^{\mathrm{a}}$ & $54.3^{\mathrm{a}}$ \\
\hline & $\mathrm{SD}$ & 5.30 & 0.09 & 2.62 & 12.8 \\
\hline \multirow{2}{*}{ Cohesiveness } & Mean & $0.008^{\mathrm{a}}$ & $0.007^{\mathrm{a}}$ & $0.008^{\mathrm{a}}$ & $0.007^{\mathrm{a}}$ \\
\hline & SD & 0.002 & 0.001 & 0.001 & 0.001 \\
\hline
\end{tabular}

Means with same superscript in the same row is not different $(p>0.05)$.

${ }^{1)}$ Treatments: As shown in Table 1.

Table 6. Physico-chemical and microbiological properties in pork sausages with two levels of $\mathrm{TP}$ during storage at $1^{\circ} \mathrm{C}$

\begin{tabular}{|c|c|c|c|c|c|c|}
\hline & \multicolumn{6}{|c|}{ Parameters ${ }^{I I}$} \\
\hline & $\mathrm{pH}$ & Hunter L & Hunter a & Hunter b & TPC & VRB \\
\hline Treatment $\times$ day & NS & NS & NS & NS & NS & NS \\
\hline Treatment & $*$ & $*$ & $*$ & $*$ & NS & NS \\
\hline Day & $*$ & $*$ & $*$ & NS & $* *$ & $* *$ \\
\hline \multicolumn{7}{|l|}{ Treatment $^{2}$} \\
\hline CTL & $6.15^{\mathrm{a}}$ & $76.0^{\mathrm{b}}$ & $13.0^{\mathrm{c}}$ & $5.81^{\mathrm{c}}$ & $3.51^{\mathrm{a}}$ & $2.47^{\mathrm{a}}$ \\
\hline REF & $6.16^{\mathrm{a}}$ & $76.3^{\mathrm{a}}$ & $12.8^{\mathrm{c}}$ & $5.87^{\mathrm{c}}$ & $3.69^{\mathrm{a}}$ & $2.66^{\mathrm{a}}$ \\
\hline TRT1 & $5.99^{\mathrm{b}}$ & $74.8^{\mathrm{c}}$ & $13.6^{\mathrm{b}}$ & $9.53^{\mathrm{b}}$ & $4.02^{\mathrm{a}}$ & $2.93^{\mathrm{a}}$ \\
\hline TRT2 & $5.86^{\mathrm{c}}$ & $72.3^{\mathrm{d}}$ & $14.7^{\mathrm{a}}$ & $12.0^{\mathrm{a}}$ & $3.97^{\mathrm{a}}$ & $3.07^{\mathrm{a}}$ \\
\hline \multicolumn{7}{|l|}{ Storage Day } \\
\hline 0 & $6.00^{\mathrm{b}}$ & $74.3^{\mathrm{b}}$ & $14.1^{\mathrm{a}}$ & $8.34^{\mathrm{a}}$ & $2.21^{\mathrm{d}}$ & $<2^{\mathrm{c}}$ \\
\hline 3 & $6.03^{\mathrm{ab}}$ & $74.9^{\mathrm{a}}$ & $13.7^{\mathrm{ab}}$ & $8.42^{\mathrm{a}}$ & $2.31^{\mathrm{d}}$ & $<2^{\mathrm{c}}$ \\
\hline 7 & $6.04^{\mathrm{ab}}$ & $75.0^{\mathrm{a}}$ & $13.4^{\mathrm{bc}}$ & $8.34^{\mathrm{a}}$ & $2.28^{\mathrm{d}}$ & $<2^{\mathrm{c}}$ \\
\hline 14 & $6.06^{\mathrm{a}}$ & $75.0^{\mathrm{a}}$ & $13.2^{\mathrm{c}}$ & $8.16^{\mathrm{a}}$ & $3.01^{\mathrm{c}}$ & $<2^{\mathrm{c}}$ \\
\hline 21 & $6.05^{\mathrm{a}}$ & $75.0^{\mathrm{a}}$ & $13.4^{\mathrm{bc}}$ & $8.21^{\mathrm{a}}$ & $5.81^{\mathrm{b}}$ & $3.25^{\mathrm{b}}$ \\
\hline 28 & $6.06^{\mathrm{a}}$ & $75.0^{\mathrm{a}}$ & $13.3^{\mathrm{bc}}$ & $8.41^{\mathrm{a}}$ & $7.16^{\mathrm{a}}$ & $5.44^{\mathrm{a}}$ \\
\hline
\end{tabular}

${ }^{a-d}$ Means with different superscripts in the same column (treatment) are different $(p<0.05)$.

${ }^{\text {a-d }}$ Means with different superscripts in the same column (storage day) are different $(p<0.05)$.

${ }^{1)}$ Hunter L, lightness; Hunter a, redness; Hunter b, yellowness; TPC, total plate count agar for total bacteria; VRB, violet red bile agar for Enterobacteriaceae.

2) Treatment: As shown in Table 1.

NS $=$ not significant; ${ }^{*} p<0.05,{ }^{*} p<<0.001$.

whereas redness and yellowness values were decreased with increasing tomato paste concentration. These results could be explained by the colorant in TP. Tomato contains lycopene, which is the major carotenoid that gives red and yellow color in tomato and tomato product (Friedman, 2002). Therefore, the presence of a carotenoid in TP could explain changes of the color parameters.

\section{Microbial counts}

Results of microbial counts of pork sausages with two different levels of TP during 28 days of storage under $10^{\circ} \mathrm{C}$ at the refrigerator are provided in Table 6 . Since there was no interaction between two factors (treatment and day) ( $p>0.05)$, data were pooled. During storage time, TPC and VRB were increased $(p<0.05)$. However, the addition of TP did not show the antimicrobial effect among all treatments $(p>0.05)$. Sánchez-Escalante et al. (2003) reported that addition of lycopene-rich tomato pulp, alone or mixed with ascorbic acid and/or oregano extract, did not affect the phychrotrophic bacterial counts of beef patties during storage. In contrast, Kang et al. (2010) reported antimicrobial effects of TP with olive oil in pork patty. They manufactured pork patties with TP prepared with olive oil (TPPO) containing four levels of TPPO $(0.25,0.5,0.75$, and $1.0 \%)$ and reported that incorporation of TPPO into pork patties $(0.75$ and $1.0 \%)$ de- 
creased TPC, as compared to the control on days 3 and 7 under $4^{\circ} \mathrm{C}(p<0.05)$. Therefore, additional research is needed to investigate the association of TP and other antioxidant on antimicrobial activity.

\section{TBARS}

Since there was an interaction $(p<0.05)$ between two factors (treatment and day) in the TBARS results, data were separated out and the treatment was assessed in terms of day (Fig. 2). TBARS values were increased ( $p<$ 0.05 ) with increasing storage days in all treatments. During storage under $10^{\circ} \mathrm{C}$ at the refrigerator, TBARS values did not show differences among treatments until day 21 $(p>0.05)$. However, sausage samples with TP (TRT1 and TRT2) showed lower TBARS values (0.06 and $0.08 \mathrm{mg} /$ $\mathrm{kg}$, respectively) than the control $(0.19 \mathrm{mg} / \mathrm{kg})(p<0.05)$, and not differ from reference sausage with $0.01 \%$ BHT $(0.10 \mathrm{mg} / \mathrm{kg})(p>0.05)$ at day 28 of storage. The minimum TBARS value that occurring rancid odor is $2 \mathrm{mg}$ MDA/kg sample (Greene and Cumuze, 1982). However, all samples did not exceed $1 \mathrm{mg} \mathrm{MDA} / \mathrm{kg}$ sample content during the $28 \mathrm{~d}$ of storage.

Similar results were reported by Eyiler and Oztan (2010), who reported that they manufactured frankfurters with 2 and $4 \%$ of sun-dried TP. The authors reported that TBARS values were increased but did not exceed the $1 \mathrm{mg}$ MDA $/ \mathrm{kg}$ sample during 1 month of storage under $4^{\circ} \mathrm{C}$. Therefore, these results indicated that addition of TPs into the pork sausages effectively retarded lipid oxidation until the end of storage day.

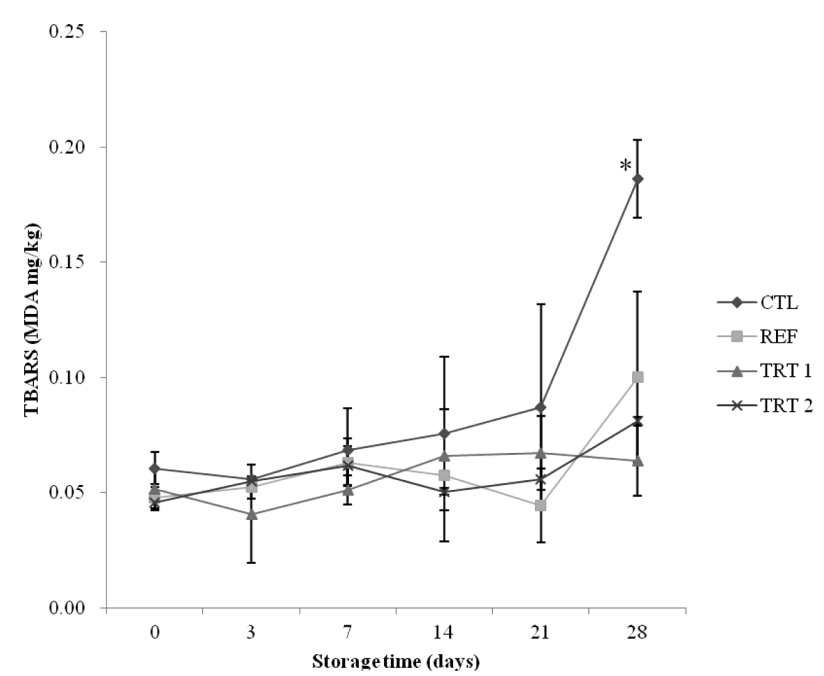

Fig. 2. TBARS (MDA mg/kg) of pork sausages with two levels of TP during storage at $10^{\circ} \mathrm{C}$. CTL, control sausage; REF, reference sausage with BHT $0.01 \%$; TRT1, treatment sausage with $1 \%$ tomato powder (TP); TRT2, treatment sausage with $2 \%$ TP. Significance level: ${ }^{*} p<0.05$.

\section{Conclusions}

In the model study, the three kinds of TPs possessed more than $2 \mathrm{~g} / 100 \mathrm{~g}$ of total phenolic compounds. The tomato water-insoluble powder showed the highest DPPH radical scavenging activity at the concentration of 1-20 $\mathrm{mg} / \mathrm{mL}(p<0.05)$. In addition, the water insoluble powder at $5 \mathrm{mg} / \mathrm{mL}$ exhibited the iron chelating ability to the comparable extent with that of EDTA. On the other hand, a concentration of $20 \mathrm{mg} / \mathrm{mL}$ was required to observe the similar results when other powders were used. These results suggested that the insoluble powder could be used as the better natural antioxidant in food system. In addition, addition of TP into the pork sausages reduced $\mathrm{pH}$ and Hunter $\mathrm{L}$ values, however it increased Hunter $\mathrm{a}$ and $\mathrm{b}$ values. Especially, lipid oxidation of pork sausages was effectively retarded with the addition of TP, regardless of the level of TP. Thus, TP could be used as an antioxidant and natural color agents in the pork sausages.

\section{Acknowledgements}

This study was financially supported by the Chonnam National University, 2011.

\section{References}

1. Anese, M., Manzocco, L., Nicoli, M. C., and Lerici, C. R. (1999) Antioxidant properties of tomato juice as affected by heating. J. Sci. Food Agric. 79, 750-754.

2. AOAC (1995) Official methods of analysis. 15th ed, Association of Official Analytical Chemists, Washington, DC.

3. Arnao, M. B., Cano, A., and Acosta, M. (2001) The hydrophilic and lipophilic contribution to total antioxidant activity. Food Chem. 73, 239-244.

4. Basuny, A. M., Gaafar, A. M., and Arafat, S. M. (2009) Tomato lycopene is a natural antioxidant and can alleviate hypercholesterolemia. Afr. J. Biotechnol. 8, 6627-6633.

5. Bázan-Lugo, E., García-Martínez, I., Alfaro-Rodríguez, R. H., and Totosaus, A. (2012) Color compensation in nitritereduced meat batters incorporating paprika or tomato paste. J. Sci. Food Agric. 92, 1627-1632.

6. Bourne, M. C. (1978) Texture profile analysis. Food Technol. 32, 62-66 (72).

7. Branen, A. L. (1975) Toxicology and biochemistry of butylated hydroxyanisole and butylated hydroxytoluene. J. Am. Oil Chem. Soc. 52, 59-63.

8. Cámara-Hurtado, M., Greve, L. C., and Labavitch, J. M. (2002) Changes in cell wall pectins accompanying tomato (Lycopersicon esculentum Mill.) paste manufacture. J. Agric. Food Chem. 50, 273-278.

9. Candogan, K. (2002) The effect of tomato paste on some qua- 
lity characteristics of beef patties during refrigerated storage. Eur. Food Res. Technol. 215, 305-309.

10. Chin, K. B., Kim, K. H., and Lee, H. C. (2006) Physicochemical and textural properties, and microbial counts of meat products sold at Korean markets. Korean J. Food Sci. An. 26, 98-105.

11. Clinton, S. K. (1998) Lycopene: Chemistry, biology, and implications for human disease. Nutr. Rev. 56, 35-51.

12. Deda, M. S., Blouka, J. G., and Fista, G. A. (2007) Effect of tomato paste and nitrite level on processing and quality characteristics of frankfurters. Meat Sci. 76, 501-508.

13. Dewanto, V., Wu, X., Adom, K. K., and Liu, R. H. (2002) Thermal processing enhances the nutritional value of tomatoes by increasing total antioxidant activity. J. Agric. Food Chem. 50, 3010-3014.

14. Eriksson, C. E. (1982) Oxidation of lipids. Food Chem. 9, 320.

15. Eyiler, E. and Oztan, A. (2010) Production of frankfurters with tomato powder as a natural additive. LWT Food Sci. Technol. 44, 307-311.

16. Friedman, M. (2002). Tomato glycoalkaloids: Role in the plant and in the diet. J. Agric. Food Chem. 50, 5751-5780.

17. Gahler, S., Otto, K., and Böhm, B. (2003) Alteration of vitamin $\mathrm{C}$, total phenolics, and antioxidant capacity as affected by processing tomatoes to different products. J. Agric. Food Chem. 51, 7962-7968.

18. Garcia, M. L., Calvo, M. M., and Selgas, M. D. (2009) Beef hamburgers enriched in lycopene using dry tomato peel as an ingredient. Meat Sci. 83, 45-49.

19. Gartner, C., Stahl, W., and Sies, H. (1997) Lycopene is more bioavailable from tomato paste than from fresh tomatoes. $\mathrm{Am}$. J. Clin. Nutr. 66, 116-122.

20. Giovanelli, G. and Paradiso, A. (2002) Stability of dried and intermediate moisture tomato pulp during storage. J. Agric. Food Chem. 50, 7277-7281.

21. Giovannucci, E. (1999) Tomatoes, tomato-based products, lycopene and cancer: Review of the epidemiologic literature. $J$. Natl. Cancer Inst. 91, 317-331.

22. Greene, B. E. and Cumuze, T. H. (1982) Relationship between TBA numbers and inexperienced panelist's assessments of oxidized flavor in cooked beef. J. Food Sci. 47, 52-58.

23. Hart, D. J. and Scott, K. J. (1995) Development and evaluation of an HPLC method for the analysis of carotenoids in foods, and the measurement of the carotenoids content of vegetables and fruits commonly consumed in the UK. Food Chem. 54, 101-111.

24. Huang, S. J., Tsai, S. Y., and Mau, J. L. (2006) Antioxidant properties of methanolic extracts from Agrocybe cylindracea. LWT Food Sci. Technol. 39, 378-386.

25. Kang, S. N., Jin, S. K., Yang, M., and Kim, I. S. (2010) Changes in quality characteristics of fresh pork patties added with tomato powder during storage. Korean J. Food Sci. An. 30, 216-222.

26. Keeton, J. T. (1994) Low-fat meat products: Technological problems with processing. Meat Sci. 36, 261-276.

27. Lavelli, V., Peri, C., and Rizzolo, A. (2000) Antioxidant acti- vity of tomato products as studied by model reactions using xanthine oxidase, myeloperoxidase, and copper-induced lipid peroxidation. J. Agric. Food Chem. 48, 1442-1448.

28. Le, K., Chiu, F., and Ng, K. (2007) Identification and quantification of antioxidants in Fructus lycii. Food Chem. 105, 353-363.

29. Lee, H. S. (1992) Antioxidative activity of browning reaction products isolated from storage-aged orange juice. J. Agric. Food Chem. 40, 550-552.

30. Lin, J. Y. and Tang, C. Y. (2007) Determination of total phenolic and flavonoid contents in selected fruits and vegetables, as well as their stimulatory effects on mouse splenocyte proliferation. Food Chem. 101, 140-147.

31. Lin, L. Y., Liu, H. M., Yu, Y. W., Lin, S. D., and Mau, J. L. (2009) Quality and antioxidant property of buckwheat enhanced wheat bread. Food Chem. 112, 987-991.

32. Nilsson, J., Pillai, D., Önning, G., Persson, C., Nilsson, Å., and Åkesson, B. (2005) Comparison of the 2,2'azinobis-3-ethylbenzotiazo-line-6-sulfonic acid (ABTS) and ferric reducing anti-oxidant power (FRAP) methods to assess the total antioxidant capacity in extracts of fruit and vegetables. Mol. Nutr. Food Res. 49, 239-246.

33. Park, S. Y., Yoo, S. S., Shim, J. H., and Chin, K. B. (2008) Physicochemical properties, and antioxidant and antimicrobial effects of garlic and onion powder in fresh pork belly and loin during refrigerated storage. J. Food Sci. 73, 577-584.

34. Pietrasik, Z. (1999) Effect of content of protein, fat and modified starch on binding textural characteristics, and colour of comminuted scalded sausages. Meat Sci. 51, 17-25.

35. Rao, A. V., Waseem, Z., and Agarwar, S. (1998) Lycopene content of tomatoes and tomato products and their contribution to dietary lycopene. Food Res. Int. 31, 737-741.

36. Sánchez-Escalante, A., Torrescano, G., Djenane, D., Beltrán, J. A., and Roncalés, P. (2003) Combined effect of modified atmosphere packaging and addition of lycopene rich tomato pulp, oregano and ascorbic acid and their mixtures on the stability of beef patties. Food Sci. Technol. Int. 9, 77-84.

37. Shi, J. (2002) Lycopene: Biochemistry and functionality. Food Sci. Biotechnol. 11, 574-581.

38. Shi, J. and Maguer, M. L. (2000) Lycopene in tomatoes: Chemical and physical properties affected by food processing. Crit. Rev. Food Sci. Nutr. 40, 1-42.

39. Shinnhuber, R. O. and Yu, T. C. (1977) The 2-thiobarbituric acid reaction, an objective measure of the oxidative deterioration occurring in fats and oils. J. Jpn. Oil Chem. Soc. 26, 259-267.

40. Tonucci, L. H., Holden, J. M., Beecher, G. R., Khachik, F., Davis, C. S., and Mulokozi, G. (1995) Carotenoid content of thermally processed tomato-based food products. J. Agric. Food Chem. 43, 579-586.

41. Toor, R. K. and Savage, G. P. (2006) Effect of semi-drying on the antioxidant components of tomatoes. Food Chem. 97, 9097.

42. Vallverdú-Queralt, A., Medina-Remón, A., Martínez-Huélamo, M., Jáuregui, O., Andres-Lacueva, C., and Lamuela-Raventos, R. M. (2011) Phenolic profile and hydrophilic antioxidant ca- 
pacity as chemotaxonomic markers of tomato varieties. $J$ Agric. Food Chem. 59, 3994-4001.

43. Wada, S. and Fang, X. (2002) The synergistic antioxidant effect of rosemary extract and $\alpha$-tocopherol in sardine oil model system and frozen-crushed fish meat. J. Food Process. Pres. 16, 263-274.
44. Yen, G. C. and Hsieh, C. L. (1998) Antioxidant activity of extracts from Du-zhong (Eucommiaulmoides) toward various lipid peroxidation models in vitro. J. Agric. Food Chem. 46, 3952-3957.

$\overline{\text { (Received 2012.11.19/Revised 2013.2.4/Accepted 2013.3.19) }}$ 